\title{
Environmental Processes - an International Journal
}

\author{
Vassilios A. Tsihrintzis ${ }^{1}$
}

Published online: 26 January 2018

(C) Springer International Publishing AG, part of Springer Nature 2018

I am glad to announce that the newest journal of the European Water Resources Association (EWRA), Environmental Processes (http://www.springer.com/earth+sciences+ and+geography/engineering+geology/journal/40710), published by Springer, has been included in Emerging Citation Index (ESCI) database of Clarivate Analytics' (formerly Thomson Reuters') Web of Science.

Journals accepted for coverage in ESCI must have certain qualities: they must be peer reviewed, follow ethical publishing practices, meet technical requirements, have English language bibliographic information, and be recommended or requested by a scholarly audience of Web of Science users. Acceptance to ESCI is a first step towards being included in Science Citation Index (SCI), since journals are initially evaluated for the ESCI, and then will undergo a second review for inclusion in SCI.

Being indexed in the ESCI, Environmental Processes will be discoverable via the Web of Science, like SCI journals, with full citation counts and author information. Articles published in Environmental Processes will be included in the author's H-Index calculation, and also in any analysis conducted on Web of Science data.

The journal has also been included in Scopus since its first day of publication. It currently has completed its fourth volume. In the first four volumes, 798 papers have been submitted and 256 published covering 4182 pages. Figure 1 presents the continuous growth of the journal. The current acceptance rate of the journal is about $30.0 \%$ of submitted papers. The Cite Score of the journal is 2.02 for 2016, raised from 1.10 in 2015. According to Scopus, the journal ranks as follows in the respective categories:

Water Science \& Technology: 35th out of 184 journals

Environmental Engineering: 29th out of 99 journals

Pollution: 33rd out of 100 journals

Health, Toxicilogy \& Mutagenesis: 47th out of 102 journals

Vassilios A. Tsihrintzis

tsihrin@otenet.gr; tsihrin@survey.ntua.gr; tsihrin@ central.ntua.gr

1 Centre for the Assessment of Natural Hazards and Proactive Planning \& Laboratory of Reclamation Works and Water Resources Management, School of Rural and Surveying Engineering, National Technical University of Athens, 9 Iroon Polytechniou St., Zografou, 15780 Athens, Greece 


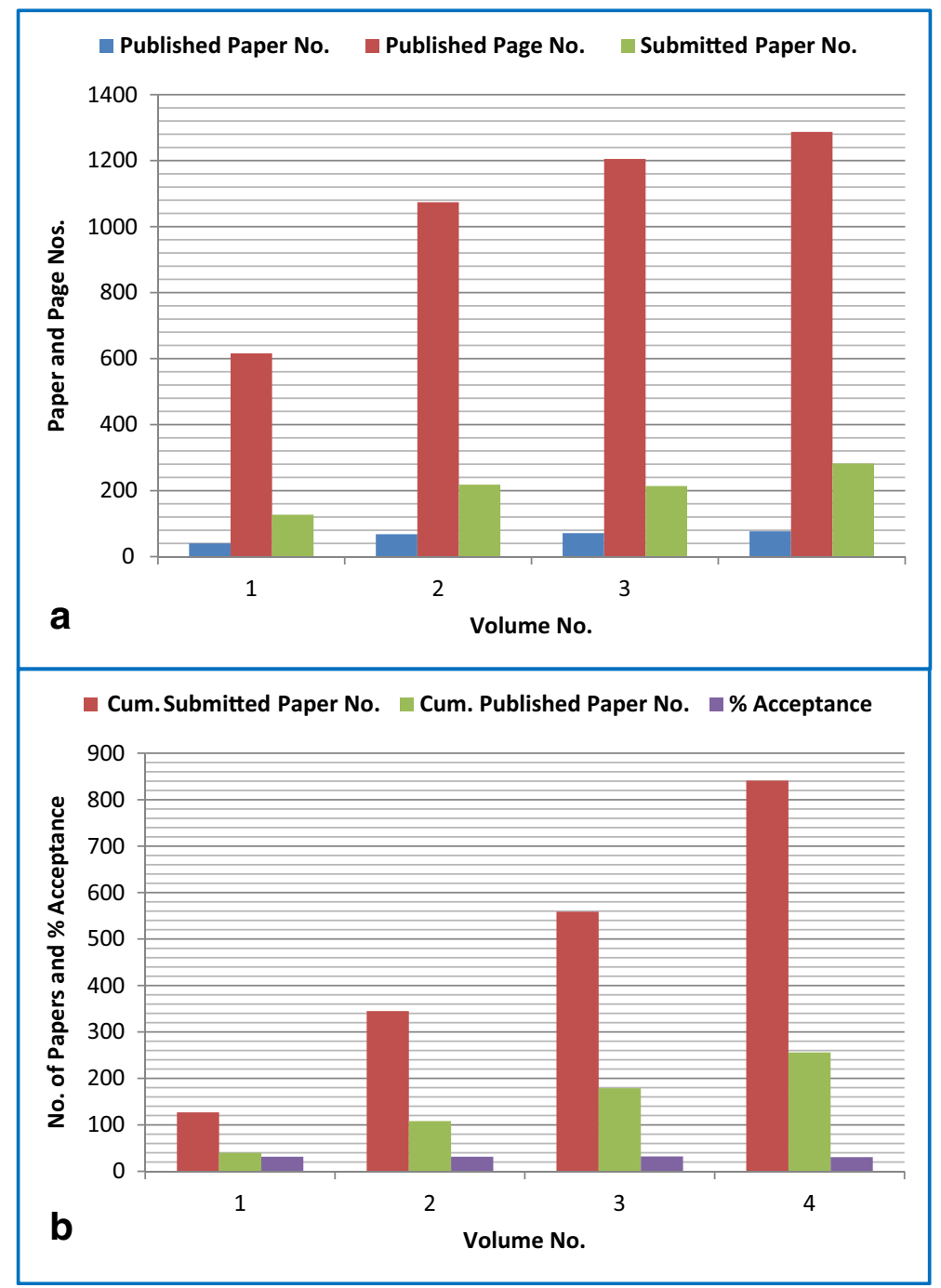

Fig. 1 Statistics for volumes 1 (2014) to 4 (2017) of Environmental Processes: a number of submitted and published papers, and published page numbers per publication year; and $\mathbf{b}$ cumulative number of papers submitted and published, and percent acceptance rate

Management, Monitoring, Policy \& Law: 54th out of 236 journals

A full description of Environmental Processes, including, among others, its aims and objectives, subject areas covered, and submission process, is given in my first issue Editorial (Tsihrintzis 2014).

I would like to thank all the authors, the reviewers, the Editorial Board members, the European Water Resources Association (EWRA), EWRA's president Professor George Tsakiris, and Springer (Ms. Petra van Steenbergen and all the production staff) for making the journal a success.

Professor Vassilios A. Tsihrintzis, Ph.D.

Editor-in-Chief 


\section{Reference}

Tsihrintzis VA (2014) New journal: Environmental Processes - an international journal. Environ Process 1:3-6. https://doi.org/10.1007/s40710-014-0015-9 